\title{
Charles-Marie de La Condamine oder die Erde als ausgebeulte Kugel
}

Bleiben wir bei der Lust des Wissens, bei der Lust am Wissen. Dabei möchte ich im Folgenden - von Ausnahmen abgesehen - in erster Linie Reiseberichte und Reisen berücksichtigen, die sich im Spannungsfeld zwischen Europa und Amerika transatlantisch ansiedeln. Auf diese Weise sind französische Reiseberichte, die sich mit den spanischen Kolonien und den spanisch-amerikanischen Besitzungen in der Neuen Welt beschäftigen, für alle Studierenden von großem Interesse, überschneiden sich doch hier die unterschiedlichsten Fachgebiete auf eine fruchtbare Weise und zeigen diese Texte doch Problematiken auf, die im Übrigen auch für die Allgemeine und Vergleichende Literaturwissenschaft wertvolle Hinweise liefern können. Dabei werden nicht allein Romanistik, Germanistik und die anglophonen Philologien berührt, sondern komparatistisch unterschiedlichste Weltregionen miteinander verglichen, ohne dabei allgemeine Fragestellungen in diesem historisch-chronologischen Teil der Vorlesung aus den Augen zu verlieren.

Mit der Reise von La Condamine und anderer Teilnehmer einer Expedition, die von der französischen Académie des Sciences ausgesandt die spanischen Kolonien in Amerika zum Ziel hatte, beginnt in gewisser Weise eine neue Etappe innerhalb der Reiseliteratur, vor allem aber der Auseinandersetzung Europas mit Amerika. Denn es sind nun nicht mehr die iberischen Conquistadoren, Missionare oder Abenteurer, die diese Reise in die Neue Welt spült, sondern Boten eines wissenschaftlichen Interesses und wissenschaftlicher Fähigkeiten, zu deren Ziel im 18. Jahrhundert der amerikanische Kontinent in steigendem Maße wurde. Denn für viele Wissenschaftler des 18. und auch noch des 19. Jahrhunderts war Amerika - und insbesondere das tropische Amerika - ein wahres Eldorado des Wissens und zugleich der Wunder. Denn diese Neue Welt war alles andere als zufriedenstellend untersucht und harrte noch jener Beschreibungen, die einen modernen Blick - und den Blick der Moderne - auf die Amerikas eröffnen sollten.

Kommen Sie heute nach Quito, der Hauptstadt von Ecuador, dann können Sie einen Bus zu jenem Punkt wenige Kilometer nördlich der Andenstadt nehmen, wo der Äquator die Andenkette im heute danach benannten Ecuador schneidet. Sie werden nicht nur eine monumentale Anlage vor sich haben, sondern zugleich auch bemerken, wie groß noch heute die Verehrung für all jene französischen Wissenschaftler ist, die nicht zu Zwecken der Eroberung das damalige Teilgebiet des spanischen Weltreiches bereisten. Sie kamen als académiciens, als Mitglieder der Französischen Akademie der Wissenschaften, vorsichtig beäugt und kontrolliert von den spanischen Kolonialbehörden, denen sie als

Ә Open Access. () 2020 Ottmar Ette, publiziert von De Gruyter. (cc) BY-NC-ND Dieses Werk ist lizenziert unter der Creative Commons Attribution-NonCommericial-NoDerivatives 4.0 Lizenz.

https://doi.org/10.1515/9783110650686-017 
potentielle Unruhestifter galten. Doch im Grunde führten die Franzosen nichts Böses im Schilde, sondern versuchten allein, eine wissenschaftliche Frage einer wissenschaftlichen Antwort zuzuführen. Etwas flapsig könnten wir die Frage so stellen: Ist die Erde eine geometrische Kugel oder aber ausgebeult?

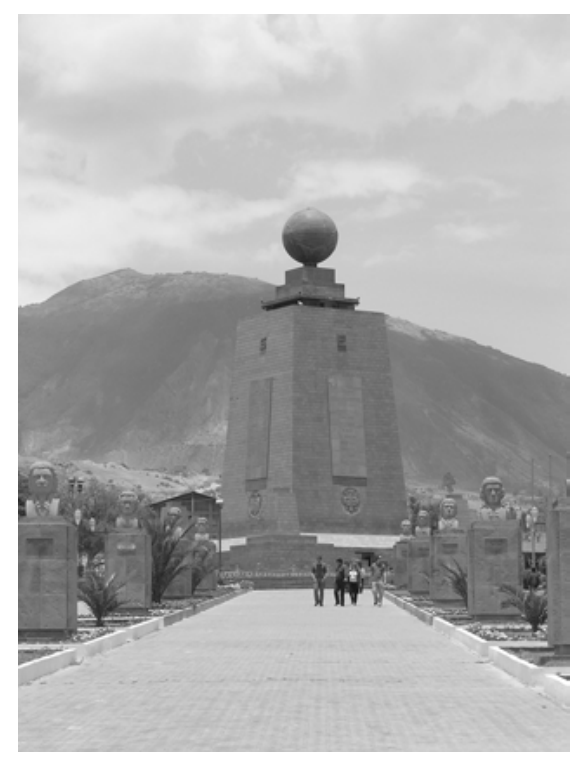

Abb. 56: Äquatormonument „Mitad del Mundo" in San Antonio de Pichincha bei Quito, zum Gedenken an die französische Vermessungsexpedition.

Daher war die Frage, welche diese gelehrten Franzosen umtrieb, eine Fragestellung der abstrakteren Art: Wie nämlich ist die Erde beschaffen? Besitzt sie eine Kugelgestalt, ist sie eher elliptisch, ist sie abgeplattet oder aber ausgebuchtet an den Polen und am Äquator? Diese Probleme waren keineswegs geklärt. Christoph Columbus hatte entgegen aller Überlieferungen und Legenden die Erde nicht mit einer Kugel verglichen - und übrigens auch nicht mit einem Ei, dem sogenannten 'Ei des Columbus' -, sondern mit einer Frucht, genauer einer Birne, wobei er dieser Vorstellung zugleich noch einige mittelalterliche Akzente zugesellte, indem er dieser Birne in etwas krasser Metaphernsprache eine - wie er sich ausdrückte - weibliche Brust aufsetzte. Die Spitze dieser Brust zeigte das Paradies an, erhoben über den Läuterungsberg. Auch in der Vorstellungswelt von Dante Alighieri sowie in seiner göttlichen Commedia finden Sie derlei Vorstellungen.

All dies entbehrte nicht der christlichen Logik. Dieses irdische Paradies musste ja erhoben und erhaben sein, damit von ihm auch die vier Flüsse des Paradieses herabfließen und die weite Welt befruchten konnten. Vor einem dieser gewaltigen Flüsse glaubte sich Columbus ja auch in der Tat im Mündungsbereich 
des Orinoco, als er weit draußen auf hoher See noch immer Massen von Süßwasser ausmachen konnte, die sich noch nicht mit dem Salzwasser des Meeres gemischt hatten. Nicht anders brachten auch europäische Reisende am Amazonas die Größe dieses Flusses mit den Paradiesversprechungen der Bibel in einen $\mathrm{Zu}$ sammenhang, schien alles doch den Voraussagungen der Heiligen Schrift genauestens zu entsprechen.

Columbus war jedoch keineswegs der einzige, der die Erde mit einer Frucht verglich. Denn der erste Globus der Menschheit entstand kurze Zeit vor der Kunde des Columbus; und sein Erfinder, der deutsche Gelehrte Martin Behaim, hatte ihm die Form eines Apfels gegeben, eines Erdapfels also, den Sie im übrigen noch heute im Germanischen Nationalmuseum zu Nürnberg bewundern können. Es war also gar nicht so abwegig, der Erde nicht die streng geometrische Form einer Kugel zu verleihen. Wie aber sah der Planet Erde wirklich aus?

Die Frage nach der genauen Gestalt der Erde, deren Globalität spätestens mit der Reise des Columbus und nach ihm der ersten Weltumsegelung von Magellan oder Magalhães eine bewiesene Sache war, bot von Beginn an genügend Stoff für allerlei Legenden und Mutmaßungen. Isaac Newton etwa vertrat die These, dass die Erde ein Ellipsoid sei mit abgeflachten Polen und einem ausgebuchteten Äquatorbereich, also durchaus nicht so aussehend, wie jene Version des Erdglobus, die wir alle vielleicht einmal in unserem Kinderzimmer - oder auch Studierzimmer - gehabt haben.

Gegen Newtons These freilich gab es früh und vor allem in Frankreich Widerstand, vor allem durch den Astronomen Cassini. Daher entschied sich die französische Académie des Sciences dafür, zwei Expeditionen auszurüsten und in verschiedene Richtungen zu schicken. Eine erste wurde unter der Leitung von Maupertuis ausgesandt, den wir als den von Friedrich dem Großen eingesetzten Präsidenten der Königlich Preußischen Akademie der Wissenschaften zu Berlin kennen. Sie führte ihn und seine Kollegen nach Lappland, eine Reise, die Voltaire in einem seiner contes philosophiques einen langanhaltenden literarischen Ruhm verschaffte.

Eine zweite Expedition sollte zeitgleich eine französische Wissenschaftlergruppe zum Äquator führen, um dort ebenfalls entsprechende Messungen und Studien zu betreiben. Wenn man in der französischen Akademie der Wissenschaften zum damaligen Zeitpunkt den Globus drehte, dann zeigte sich rasch, dass sich als einzig zugängliche Region die Audiencia de Quito anbot, die sich wie gesagt im Bereich des aktuellen Ecuador befindet. Die Leitung dieser Expedition wurde dem Mathematiker Louis Godin anvertraut. CharlesMarie de La Condamine war zum damaligen Zeitpunkt nur ein einfacher Teilnehmer dieser Expedition, doch sollte er aus verschiedenen Gründen recht bald deren eigentlicher Leiter werden. 


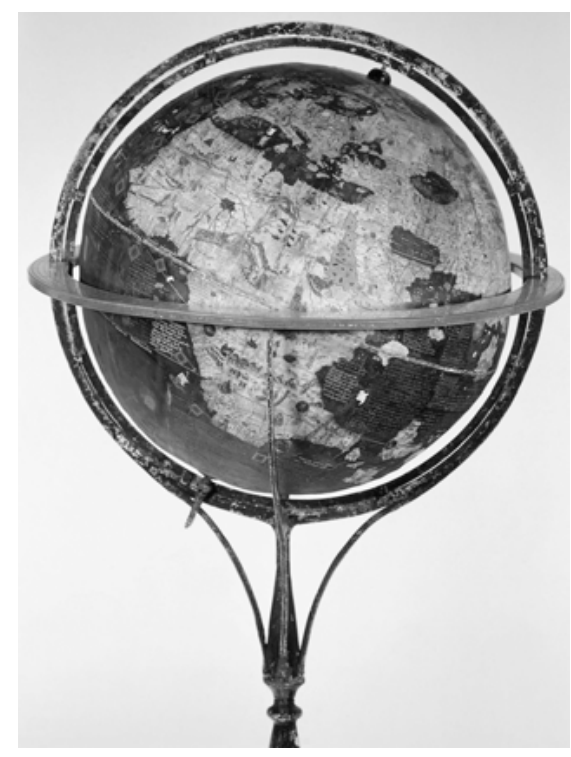

Abb. 57: Martin Behaims Erdapfel.

Zur Welt gekommen war La Condamine mit dem neuen Jahrhundert im Jahre 1701 in Paris, eine Welt, die er nach genauen Messungen im Jahre 1774 wieder verließ. Es sind entscheidende Jahre der französischen Aufklärung. La Condamine schlug zunächst die militärische Laufbahn ein, bevor er sich, freilich früh schon, den - im damaligen Sinne verstandenen - Naturwissenschaften und sciences physiques zuwandte. Bereits 1730 wurde er dabei in die französische Académie des Sciences aufgenommen, in deren Auftrag er im folgenden Jahr bereits eine Reihe von Fragen des Mittelmeerraumes klären sollte und insbesondere die nordafrikanische Küste erforschte.

Dann kam die große Aufgabe seines Lebens. Frankreich war in dieser Frage der Erdgestalt tief gespalten: Auch ein Voltaire unterstützt im Übrigen die These Isaac Newtons gegen Cassini. Eine Entscheidung musste gefunden werden. Voltaire war mit La Condamine befreundet; und Hélène Minguet ${ }^{1}$ mutmaßt wohl nicht zu Unrecht, dass Voltaire bei der Wahl La Condamines in die Pariser Akademie eine nicht unbedeutende Rolle gespielt haben dürfte.

Die Franzosen wollten damit in spanische Besitzungen in Amerika aufbrechen, um dort Messungen und Untersuchungen durchzuführen. Das europäische Siècle des Lumières zeigte sich wissenschaftlich über die Grenzen hinweg

1 Minguet, Hélène: Introduction. In: La Condamine, Charles-Marie de: Voyage sur l'Amazone. Paris: François Maspero 1981, S. 5-27. 


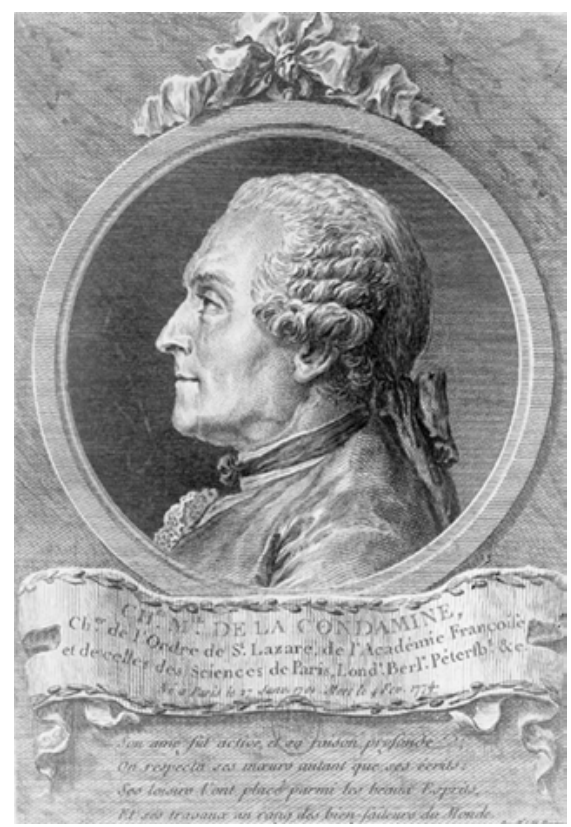

Abb. 58: Charles-Marie de la Condamine (Paris, 1701 - ebenda, 1774).

verbunden. Der spanische Hof gab sein placet relativ leicht, wenn man auch beschloss, die nie ungefährlichen Franzosen unter Bewachung zu stellen oder, sagen wir vornehmer, von spanischen Offizieren begleiten zu lassen. Übrigens wurden später die französischen Orientierungsmarken der geometrischen, geodätischen und astronomischen Messungen, welche die Académiciens im spanischen Amerika durchführten, wieder zerstört, da sie das französische Königswappen, die bourbonischen Lilien, in provokativer Größe auf spanischem Grund entfalteten. Aber dies waren allenfalls Begleiterscheinungen, welche die Expedition der französischen académiciens selbst nicht behinderten.

Sie wissen sicherlich, dass man auch heute noch Messungen durchführt, um die Frage nach der genauen Gestalt der Erde zu klären. Dabei hat man es in unserer Zeit freilich leichter, kann man die Erde doch sozusagen von außen, aus dem Weltraum - sogar schon als Tourist -, sehen, fotographieren und selbstverständlich auch messen. Damals verfügte man über eine Reihe terrestrischer Methoden, von denen die Triangulationsmethode besonders zuverlässig war, wobei man den zu messenden Bereich in Dreiecke einteilte, die man dann durch kleine Pyramiden kennzeichnete. Bereits 1670 hatte man in Frankreich mit Hilfe dieser methode einen Meridiansbogen ausgemessen, so dass man über einen Vergleichspunkt verfügte, der mit den Messungen in Lappland und Ecuador in Relation gesetzt werden konnte. 


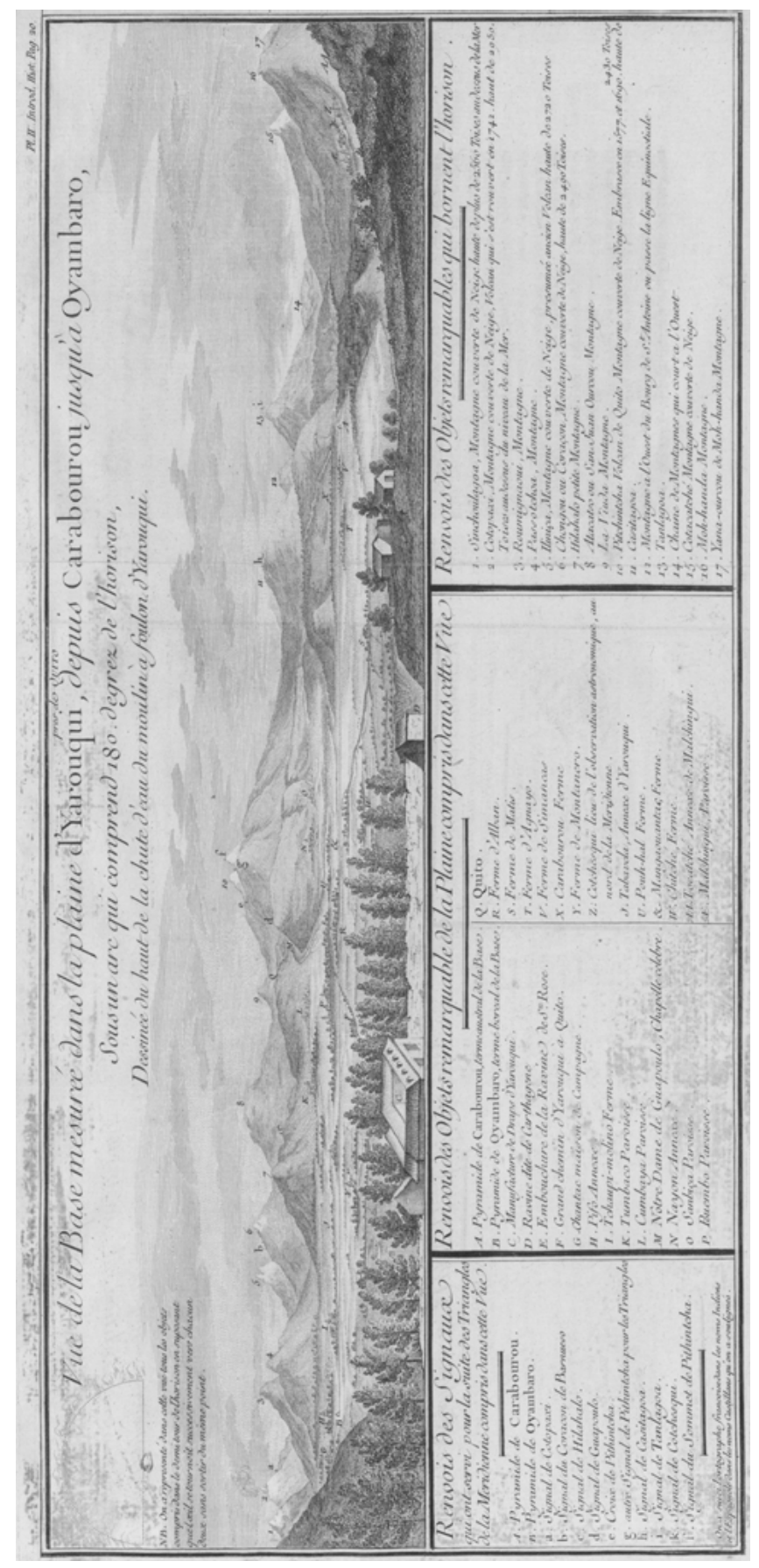

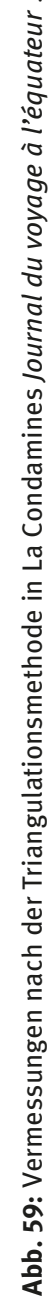




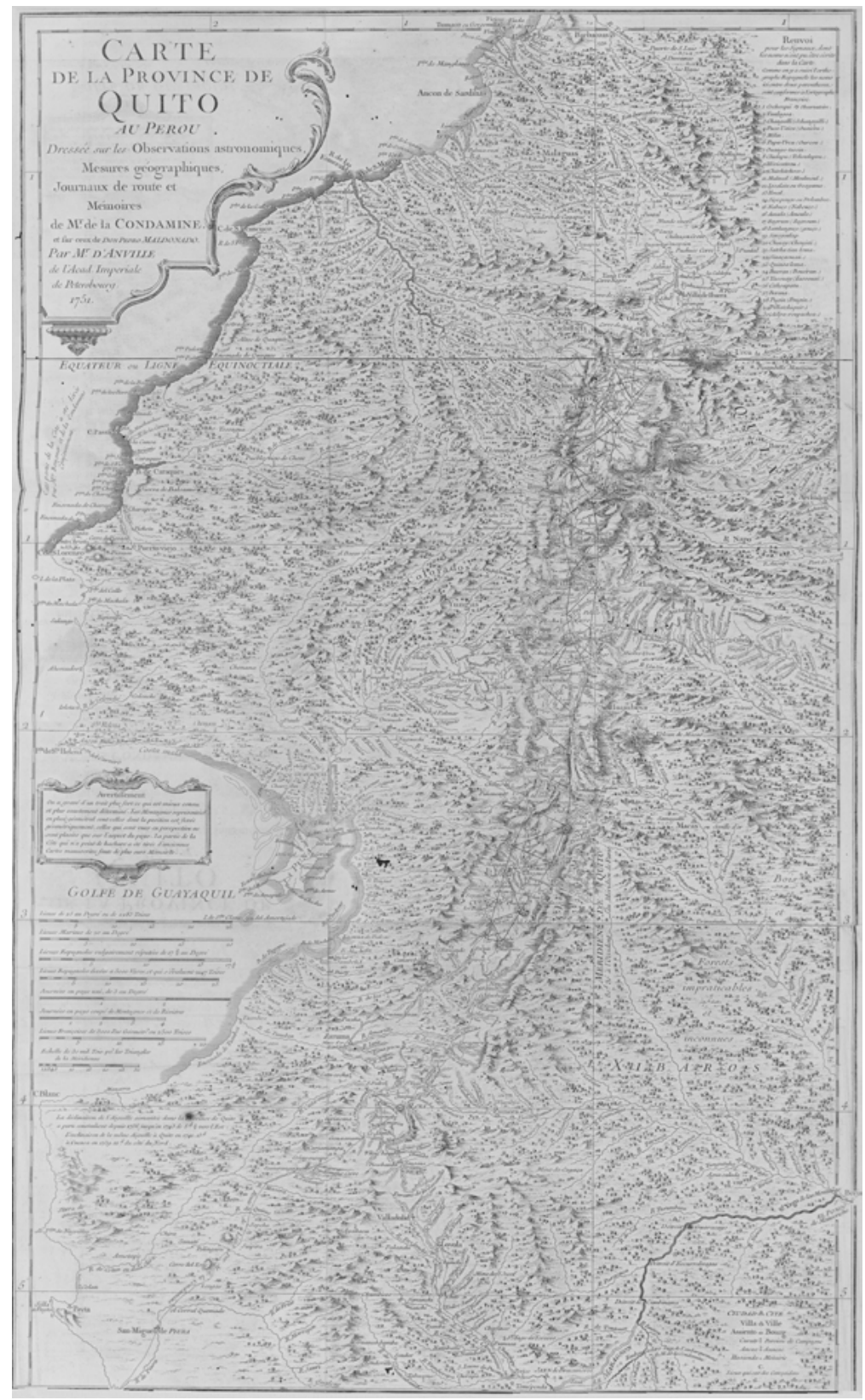

Abb. 60: Vermessungen und Kartographierung nach der Triangulationsmethode in La Condamines Journal du voyage à l'équateur ... . 


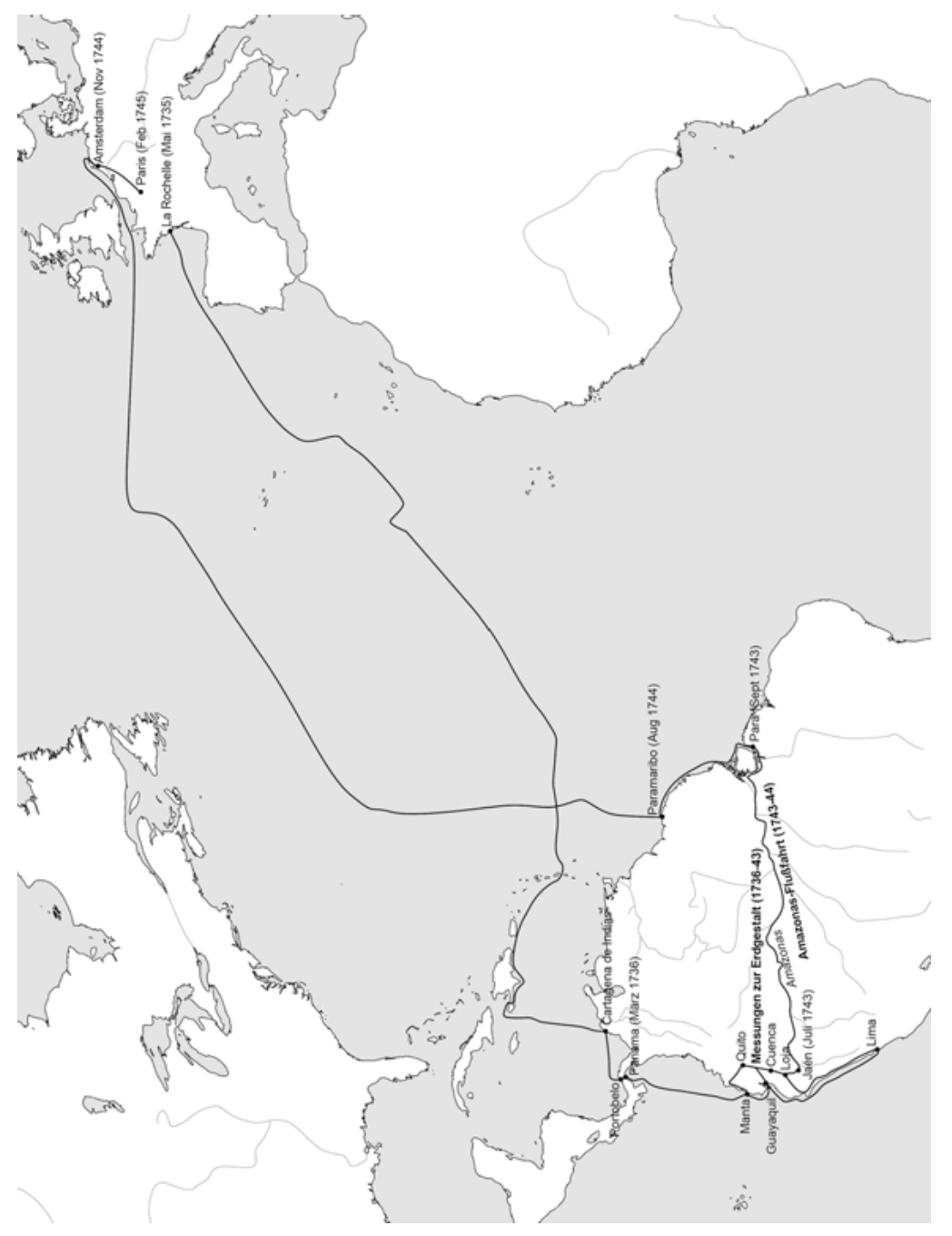

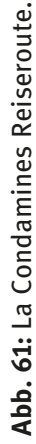


Die einst von Colbert gegründete Académie des Sciences hatte nun verschiedene Wissenschaftler mit der Berechnung der Oberfläche Frankreichs beauftragt. Diese Arbeiten wurden 1682 mit einer deutlichen Verbesserung der Karte von Frankreich abgeschlossen. Jene Erfahrungen wurden nun durch die Wissenschaftlergruppen auf die Messung des Äquatorialbogens übertragen. Es galt also nur, professionelle Messergebnisse zu erstellen - und das Rätsel um die Kugelgestalt der Erde war gelöst.

Nun, ganz so einfach war die Umsetzung dieser Ziele leider nicht. Im Mai 1735 segelt ein französisches Kriegsschiff von La Rochelle aus los, an Bord ein Team von zehn Wissenschaftlern, die von der Académie für diese Untersuchung ausgewählt wurden. Unter diesen Wissenschaftlern befenden sich der Mathematiker und Astronom Louis Godin, der Astronom und Mathematiker Pierre Bouguer, der Naturalist und Arzt Joseph de Jussieu, ein Geograph, ein Uhrenspezialist - was, wie wir gleich einsehen werden, besonders wichtig war -, ein Ingenieur, ein Techniker, ein Chirurg sowie eben unser La Condamine. Diese Gruppe wurde in Cartagena durch die kolonialspanischen Behörden in Emfpang genommen.

Zwei Leutnants der spanischen Marine kümmerten sich um die französischen Gäste, nämlich Jorge Juan y Santacilia sowie Antonio de Ulloa, die durch ihre Tätigkeiten und Kenntnisse in der Erforschung Amerikas ebenfalls zu Berühmtheiten wurden. Sie sollten die französischen Wissenschaftler überwachen und zugleich versuchen, ihre Kenntnisse mit denen der Franzosen zu vergleichen.

Die Reise führte die Gruppe von Cartagena de Indias nach Portobelo, dann weiter über den Río Chagres und zu Fuß nach Panamá am Pazifischen Ozean, von dort dann nach Manta und Guayaquil, den Haupthafen im heutigen Ecuador. La Condamine und Bouguer verließen die Expedition bereits in Manta und begannen mit ihren Messarbeiten schon auf dem Weg nach Quito. Durch die astronomische Beobachtung der Mondfinsternis von 1736 gelang es ihnen, den genauen Verlauf der Küste festzulegen, die in diesem Bereich den westlichsten Vorsprung der Küste Südamerikas bildet. So gelang ihnen eine grundlegende Berichtigung der Karten dieses Teiles des Kontinents.

Aber längst nicht alles verlief so planmäßig. Die unterschiedlichen Forschungen der Franzosen wurden argwöhnisch von den spanischen Kolonialbehörden auch vor Ort beäugt. Die bereits zitierte Hélène Minguet verwies darauf, die spanischen Regierungsbeamten hätten den Verdacht geschöpft, dass die Franzosen den Plan gefasst haben könnten, sich des Schatzes der Incas zu bemächtigen. Dieser sagenumwobene Schatz geisterte noch immer durch alle Imaginationen und wurde flugs hervorgekramt, um deswegen Ausländer zu inkriminieren. Wir kennen dieses Verfahren, es ist so alt wie die Menschheit selbst. 
Als die Franzosen 1739 in Cuenca und damit im Hochland ankamen, erfuhren sie, dass Maupertuis und seine Expedition aus Lappland zurückgekehrt seien und die These Isaac Newtons bestätigt wurde: Die Erde, dies wusste man also bereits, ist an den Polen abgeplattet und am Äquator ausgebuchtet. Damit stand auch fest, dass die Expedition nicht mehr als erste den Nachweis für diese Hypothese würde erbringen können. Damit war im Grunde die Aufgabe der Expedition wie auch diese selbst erledigt. Was blieb nun noch zu tun?

Das weitere Geschick der französischen Wissenschaftlergruppe ist als eher bescheiden zu bezeichnen, Denn rasch stellen sich allerlei Probleme und Auseinandersetzungen ein, die unter anderem auch zur Ermordung eines der Expeditionsmitglieder führen. Die Atmosphäre um die Franzosen verdüstert sich zunehmend: Verdächtigungen schießen ins Kraut, manchen Expeditionsmitgliedern wird Spionage unterstellt, La Condamine und seine Begleiter werden sogar vor Gericht gestellt. Damit nicht genug: 1743 schließlich bricht der Streit zwischen Bouguer und La Condamine offen aus, Bouguer bricht alle laufenden Arbeiten ab und reist nach Cartagena de Indias, um sich von dort aus nach Frankreich einzuschiffen. La Condamine fühlt sich daher frei, dem Vorschlag des Forschers Maldonado zu folgen und den Amazonas hinunterzufahren, um von dessen Mündung aus dann den Rückweg nach Frankreich anzutreten. Die Expedition zerfällt in ihre Einzelteile: Es scheint nur mehr ein Scherbenhaufen übrig zu bleiben.

Wäre da nicht die Reise von Charles-Marie de La Condamine gewesen und ihr von ihm kunstvoll verfasster Bericht. Diese Reise führte den französischen Naturforscher und Wissenschaftler zunächst nach Loja in den Hochanden, das zum damaligen Zeitpunkt für seine Fieberrinde berühmt war, und von dort hinunter nach Borja, den Übergang in das Tiefland am Amazonas. Wir haben uns diese Passage ja bereits im theoretisch-methodologischen Teil unserer Vorlesung näher angeschaut. Darauf wollen wir nicht zurückkommen.

Was folgt, ist eine faszinierende Flussfahrt mit der Untersuchung von Flora und Fauna des Amazonas-Tieflands, wobei viele Gegenstände und Phänomene bis zu diesem Zeitpunkt in Europa völlig unbekannt waren. La Condamine bemüht sich, Neueres über die Flussverbindung zwischen dem Amazonas und dem Orinoco über den Río Negro und den Casiquiare herauszufinden, zweifelt aber an dieser tatsächlich existierenden Gabelteilung, die später von Alexander von Humboldt nachgewiesen werden sollte. Er erforscht auch die Existenz oder Nicht-Existenz der Amazonen, jener mythenumwobenen kriegerischen Frauen, gegen welche die spanischen Conquistadoren des 16. Jahrhunderts gekämpft zu haben vorgaben und die dem Fluss in der Nachfolge dieses unter anderem von Orellana transponierten Mythos auch bis 
heute seinen Namen gaben. Eine schöne Aufgabe für einen mit den Mythen der abendländischen Antike bestens vertrauten Forscher!

Doch Jean-Marie de La Condamine steht nach seiner Rückkehr aus Amerika nach Frankreich vor einem doppelten Problem. Zum einen war die Frage nach der Abplattung der Pole und der Ausbuchtung des Äquators und damit die Bestätigung der Newton'schen These längst - wie wir sahen geklärt, so dass Angaben und Messungen hierzu als völlig redundant angesehen werden mussten. Und zum anderen war Pierre Bouguer La Condamine zuvorgekommen. Denn er war lange vor ihm nach Frankreich zurückgekehrt und hatte ausführlich nicht zuletzt in Vorträgen vor der Académie des Sciences über die Ergebnisse der Expedition berichtet. Damit war klar, dass La Condamine auch auf diesem Gebiet kaum Lorbeeren in Frankreich würde ernten können.

Der mit La Condamine verfeindete Pierre Bouguer hatte bereits im November 1744 von der Reise in die Audiencia de Quito und nach Peru berichtet. Was blieb da zu tun? Denn La Condamine konnte seinerseits erst im April 1745 wieder vor der französischen Akademie der Wissenschaften auftreten. Er versäumte es nicht, dies zu tun; aber bereits bei dieser Gelegenheit trug er einen gekürzten Bericht von seiner Reise über den Amazonas vor. Er hatte seine Strategie notgedrungen geändert.

La Condamine verstand es dabei, die Aufmerksamkeit seiner Zuhörerund später seiner Leserschaft gerade dadurch zu gewinnen, dass er in recht kunstvollen Perioden nicht nur einen Bericht seiner Reise bot, sondern zugleich auch auf eine Vielzahl der einschlägigen Mythen einging: Vom Amazonen-Mythos über die vermeintliche Sage von der Flussgabelung zwischen Amazonas und Orinoco bis hin zur berühmten Legende um den Dorado vom Parime. Dies bot reichlich Stoff zum Ausschmücken und vor allem interessanten Stoff für ein breites Publikum in Frankreich, das die Behandlung derartiger Themen von einem französischen Reisenden verlangte. Und der Franzose kam diesem Verlangen nach.

La Condamine versuchte zudem, die bisherige Entdeckungs- und Eroberungsgeschichte des Marañón und des Amazonas darzustellen: Von den Fahrten Orellanas bis zum Pater Fritz, besonders aber auch jene legendenträchtige Reise des Lope de Aguirre den Amazonas hinunter, die schon zur Zeit von La Condamine nicht nur zu verschiedentlichen literarischen Bearbeitungen geführt hatte, sondern in neuerer Zeit zu einer wahren Flut an literarischen Darstellungen und Romanen, aber darüber hinaus auch den Ausgangspunkt für die monumentale Filmfassung Werner Herzogs mit dem Titel Aguirre oder der Zorn Gottes bot. Zumindest diese berühmte Verfilmung und Deutung des Aguirre-Stoffes, dem einmal eine ausführliche Habilitationsschrift gewidmet 
wurde, ${ }^{2}$ werden Sie sicherlich schon aufgrund der Starbesetzung mit Klaus Kinsky in der Hauptrolle kennen. Sie sehen, wir befinden uns in einem mythenreichen und bis heute mythenreich gebliebenen Land.

Im Mai 1743 trat La Condamine seine Reise von Tarqui aus an, wobei er zunächst einen Umweg wählen muss, da die Mörder seines ehemaligen Mitreisenden ihm einen Hinterhalt legen, um jegliche Prozessakten und Aktennotizen auf dem einfachsten Wege zu vernichten. Am 4. Juli 1743 beginnt dann die eigentliche Flussfahrt La Condamines; am nächsten Tag schon ist der Marañón, der obere Amazonas also, erreicht. Schließlich wird der Pongo de Manseriche durchquert, wobei der Begriff Pongo gleich Tor hier sowohl landschaftlich als auch reiseliterarisch überaus zutreffend ist, verwandelt La Condamine diese Passage doch - wie wir sahen - in einen glänzend formulierten und durchdachten literarischen Höhepunkt seines gesamten Reiseberichts. Denn der Pongo eröffnet gleichsam den zentralen Bereich seines Amazonas-Berichtes. damit aber befinden wir uns im Herzen jener Welt, die La Condamine nun meisterhaft darzustellen vermag und die wir uns bereits näher angesehen hatten.

Unmittelbar im Anschluss an diese Eingangs-Passage schließt sich eine zweite sehr wichtige Passage an, welche die Frage der Ureinwohner, der Indianer also, berührt. La Condamine versucht, dem französischen beziehungsweise europäischen Lesepublikum einen allgemeinen Eindruck von der indigenen Bevölkerung im Allgemeinen und von den Bewohner des Amazonas im Besonderen zu vermitteln. Wir müssen uns an dieser Stelle auf die zentralen Elemente dieser Passage beschränken:

Avant que de passer outre, je crois devoir dire un mot du génie et du caractère des originaires de l'Amérique méridionale, qu'on appelle vulgairement, quoique improprement, Indiens. Il n'est pas ici question des créoles espagnols ou portugais, ni des diverses espèces d'hommes produites par le mélange des Blancs d'Europe, des Noirs d'Afrique et des Rouges d'Amérique, depuis que les Européens y sont entrés et y ont introduits des Nègres de Guinée. [...]

Il faudrait donc, pour donner une idée exacte des Américains, presque autant de descriptions qu'il y a de nations parmi eux; cependant, comme toutes les nations d'Europe, quoique différentes entre elles en langues, moeurs et coutumes, ne laisseraient pas d'avoir quelque chose de commun aux yeux d'un Asiatique qui les examinerait avec attention, aussi tous les Indiens américains des différentes contrées que j'ai eu occasion de voir dans le cours de mon voyage m'ont paru avoir certains traits de ressemblance les uns avec les autres; et (à quelques nuances près, qu'il n'est guère permis de saisir à un voyageur qui ne voit les choses qu'en passant) j'ai cru reconnaître dans tous un même fond de caractère.

2 Vgl. Galster, Ingrid: Aguirre oder Die Willkür der Nachwelt. Die Rebellion des baskischen Konquistadors Lope de Aguirre in Historiographie und Geschichtsfiktion (1561-1992). Frankfurt am Main: Vervuert 1996. 


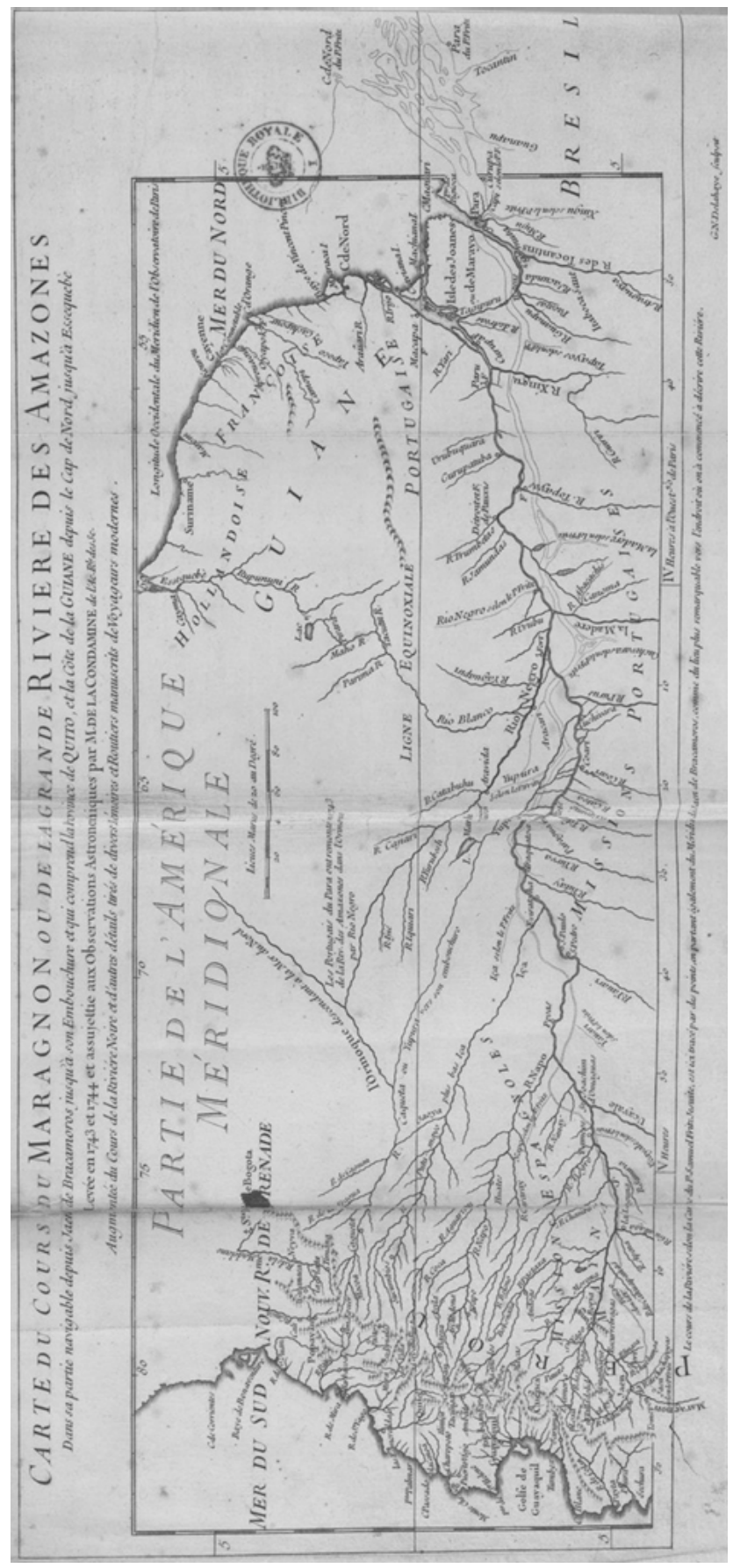

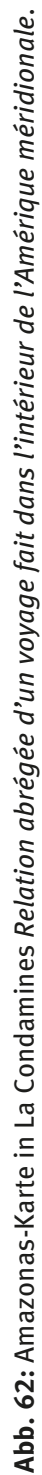


L'insensibilité en fait la base. Je laisse à décider si on la doit honorer du nom d'apathie, ou l'avilir par celui de stupidité. Elle naît sans doute du petit nombre de leurs idées, qui ne s'étend pas au-delà de leurs besoins. Gloutant jusqu'à la voracité, quand ils ont de quoi se satisfaire; sobres, quand la nécessité les y oblige, jusqu'à se passer de tout sans paraitre rien désirer; pusillanimes et poltrons à l'excès, si l'ivresse ne les transporte pas; ennemis du travail, indifférents à tout motif de gloire, d'honneur ou de reconnaissance; uniquement occupés de l'objekt présent, et toujours déterminés par lui; sans l'inquiétude pour l'avenir; incapables de prévoyance et de réflexion; se livrant, quand rien ne les gêne, à une joie puérile, qu'ils manifestent par des sauts et des éclats de rire immodérés, sans objet et sans dessin; ils passent leur vie sans penser et ils vieillissent sans sortir de l'enfance, dont ils conservent tous les défauts. ${ }^{3}$

Ja, das ist fürwahr starker Tobak! Diese Passage macht deutlich, wie sehr die Einschätzung der Indianer - sehr zurückhaltend formuliert - bestimmten Gesetzlichkeiten interkultureller Wahrnehmung gehorcht. Denn das hier entfaltete Bild der indigenen Bevölkerung entspricht genauestens jenen Vorurteilen, die man in Europa mit den 'Indianern' im 18. Jahrhundert zu verbinden pflegte und bestätigt alle Stereotype, die sich gerade auch in den nachfolgenden Debatten im Europa der Aufklärung über die Amerikaner verfestigen sollten. Doch sehen wir uns die Dinge im Einzelnen an.

Da ist zum einen die Frage der Heterogenität, der Mannigfaltigkeit, die in irgendeiner Weise behandelt und überwunden werden muss, um ein einheitliches Gesamtbild - in diesem Falle der indigenen Bevölkerung - zu liefern. Gewiss ist hierbei die extreme Sprachenvielfalt, die Vielzahl an höchst unterschiedlichen Sprachen, aber auch Ethnien und Völkerschaften, ein nicht hinwegzuleugnendes Faktum. La Condamine macht mit dieser Diversität indigener Lebensformen kurzen Prozess, stellt sie kurz fest, um dann umso besser und allgemeiner alle Völkerschaften über denselben Leisten, einen europäischen Leisten, zu schlagen.

Dies gelingt dem Franzosen mit Hilfe eines kleinen Kunstgriffs, indem er vor Augen führt, wie unterschiedlich die einzelnen europäischen Nationen sind, wie gleichförmig sie aber doch einem außenstehenden Beobachter - wie etwa einem Asiaten - erscheinen müssten, wenn er die Europäer insgesamt in den Mittelpunkt seiner Überlegungen rückte. Von daher wird eine Art Grundlage konstruiert, wobei deutlich wird, dass hier auch nicht die Franzosen den Amerikanern entgegengestellt werden, sondern die Europäer insgesamt. So bildet sich durch eine imaginär angenommene und pro forma eingenommene Außenperspektive ganz rasch die Einheit des vermeintlich Eigenen heraus.

3 La Comdamine, Charles-Marie de: Voyage sur l'Amazone. Introduction et Notes de Hélène Minguet. Paris: F. Maspero 1981, S. $61 \mathrm{ff}$. 
Zum Zweiten wird eine Art Kautele eingeführt, insoweit der Reisende seinen eigenen Beobachterstandpunkt relativiert, insofern dieser nur derjenige des rasch Vorüberziehenden, des Vorüberfahrenden sei, der die Dinge nur en passant sehen könne. Dies ist bei einem so langjährigen Aufenthalt von La Condamine im Reich der Indianer eine eigentlich etwas überraschende Wendung. Doch die Relativierung ist reine Rhetorik. Denn sie erlaubt es dem Franzosen dann nur umso mehr, ein generelles Bild der Indianer zu zeichnen. Wie sieht dieses Bild nun aus?

Die Wahrnehmung der indigenen Bevölkerung durch La Condamine geht von einem Negativum aus: ihrer insensibilité, ihrer Gefühllosigkeit und Dumpfheit, welche alle ihre Lebensbereiche erfasse. Damit wird ein Fehlen zur Grundlage gemacht, ein Nicht-Vorhandensein, welches stets den Hinweis auf ein Vorhandensein, auf ein andernorts, in Europa, Gegebenes miteinschließt, das wiederum positiv bewertet wird. Und in der Tat sind die meisten Charakteristika, die in der Folge mit Blick auf die indigene Bevölkerung aufgezählt werden, Negativa, die für einen Mangel, für ein Fehlen stehen, das nur einen Mangel mit Blick auf Europa darstellt. Man geht folglich von etwas in Europa (ganz selbstverständlich) Gegebenem aus, um dessen Fehlen in den Amerikas zu konstatieren.

Umgekehrt werden positive Werte aus den Amerikas, die auf einen Mangel in Europa hinweisen könnten, ausgeschieden, rücken also überhaupt nicht ins Blickfeld, ja wohl nicht einmal ins Bewusstsein des scheinbar so objektiven europäischen Betrachters. Diese Passage setzt sich ungeheuer lang fort, und es ist erkenntnisreich, dass La Condamine dabei nicht nur zu der Einsicht gelangt, dass die Indianer in einem wortwörtlichen Sinne nicht auf drei zählen können, sondern dass ihnen jegliche Begrifflichkeit fehlt, die ein abstraktes Denken ermöglichen könnte. Gleichwohl bezeichnet La Condamine eine solche Fähigkeit aber gleichwohl als „universelle“. Das ist im Grunde eine contradictio in adjecto, denn wenn etwas universell oder universell gültig ist, dann muss es selbstverständlich auch überall gelten. Dies ist aber gerade nicht der Fall.

Wir sehen hier bei Charles-Marie de La Condamine all jene Elemente ausgebreitet, die zum zentralen Streitpunkt in der für das 18. Jahrhundert zentralen Berliner Debatte um die Neue Welt werden sollten. Denn die Dumpfheit, ja Stupidität der indigenen Bevölkerung, ihre Antriebslosigkeit und Unfähigkeit, in abstrakten Begriffen zu denken, ja ihr fortgesetztes Leben in einer ewigen Kindheit, die von keinerlei Anreizen gequert wird, werden zu den Kernpunkten einer Debatte, die wir uns nach diesem Ausflug zu La Condamine noch etwas genauer anschauen werden. Für den Franzosen aber sind notwendig mit den beschränkten Geistesfähigkeiten auch die Möglichkeiten, komplexere Sprachen auszubilden, notwendig begrenzt: 
Toutes les langues de l'Amérique méridionale dont j'ai eu quelque notion sont fort pauvres; plusieurs sont énergiques et susceptibles d'élégance, et singulièrement l'ancienne langue du Pérou; mais toutes manquent de termes pour exprimer les idées abstraites et universelles; preuve évidente du peu de progrès qu'ont fait les esprits de ces peuples. Temps, durée, espace, être, substance, matiére, corps, tous ces mots et beaucoup d'autres n'ont point d'équivalent dans leurs langues: non seulement les noms des êtres métaphysiques, mais ceux des êtres moraux, ne peuvent se rendre chez eux qu'imparfaitement et par de longues périphrases. Il n'y a pas de mot propre qui réponde exactement à ceux de vertu, justice, liberté, reconnaissance, ingratitude [...]. ${ }^{4}$

Wieder ist es derselbe Kunstgriff, mit Hilfe dessen La Condamine nunmehr die Sprachen der Neuen Welt beurteilt und letztlich verurteilt. In diesen Formulierungen wird deutlich, wie sehr hier von europäischen Begriffen aus auf ein amerikanisches Nicht-Begreifen geschlossen wird. In einer gleichsam sprachphilosophischen Manier wird auf die Existenz eines zivilisatorischen Fortschritts oder dessen Ausbleiben rückgeschlossen. Dabei macht La Condamine mit den amerikanischen Sprachen in toto kein großes Federlesen: Sie alle werden von ihm ob ihrer Unfähigkeit, abstrakte europäische Begriffe auszudrücken, in den Orkus der Geschichte verbannt. Dass die behaupteten 'Ausfälle' amerikanischer Sprachen gar keine sind, haben im Übrigen neuere Sprachforschungen gezeigt.

Die umgekehrte Frage, welche amerikanischen Begriffe oder Vorstellungen in unseren europäischen Sprachen nicht vorhanden sein könnten, wird selbstverständlich nicht gestellt. Dies bedeutet aber keineswegs, dass der Universalitätsanspruch - wie die obige Passage deutlich zeigt - aufgegeben würde. Im Gegenteil: Gerade auch das Aubleiben belegt ja nur, dass diese Universalitätskriterien eben nicht erfüllt sind. Mehr noch, die amerikanischen Sprachen und damit auch die amerikanischen Völker könnten noch auf längere Zeit diesen 'universellen' Kriterien nicht entsprechen. So würden sie noch lange auch sprachlich in ihren Kinderschuhen stecken bleiben.

Wir haben es hier mit einer der Argumentationsschleifen in La Condamines Diskurs zu tun, die verhindern, das jeweils für andere Kulturen Spezifische, das sie Auszeichnende, überhaupt zu erkennen. Gleichzeitig bleibt der Universalitätsanspruch des Eigenen, die Setzung der eigenen Kultur zur Universalkultur, unhinterfragt und muss auch unhinterfragt bleiben, will die Superiorität Europas nicht untergraben oder zumindest teilweise in Frage gestellt werden. Wir stoßen hier fraglos auf die grundlegenden diskursiven Muster, mit deren Hilfe die Europäer ihre Herrschaft über die Welt begründeten und ihre Überlegenheit legitimierten.

Wir können an all diesen Überlegungen La Condamines sehr deutlich erkennen, dass auch und gerade der europäische Reisende selbstverständlich die

4 Ebda., S. 62f. 
Vorstellungen seiner eigenen Kultur im Gepäck mit dabei hat, dass es also nicht darum gehen kann, den Blick des Reisenden schlicht zu privilegieren und ihm eine unmittelbare, direkte Erkenntnis der Wirklichkeit zuzugestehen. Die Dinge liegen vielmehr wesentlich komplizierter. Denn der Reisende führt gleichsam sein eigenkulturelles Archiv an Optionen, an Binarismen, an kulturellen Setzungen mit sich, mit dessen Hilfe das Andere zunächst einmal definiert wird, dann aber vor allem stets im Zeichen des Fehlens, des Mangels, des Nicht-Vorhandenseins im Bezug zur eigenen Kultur erscheint. Wir scheiden und unterscheiden von uns den Anderen, das Andere, ohne überhaupt das behauptete Eigene zu hinterfragen und eine graduelle Diversität der verschiedenen Kulturen anzunehmen. Die Todorov'sche Zwickmühle schnappt hier wie an so vielen anderen Stellen erbarmungslos zu.

Dies bedeutet, dass die 'andere' Kultur nicht als Herausforderung für die 'eigene' Kultur erfahren wird, um ihre jeweiligen Optionen und epistemischen Denkmöglichkeiten zu überprüfen. Die 'eigene' Kultur wird vielmehr zur Universalkultur oder, wie man früher gesagt hätte, zur Kultur des Menschen überhaupt. Die Europäer sehen sich selbst im Fokus und Brennpunkt aller zivilisatorischen Entwicklungslinien, ganz so, wie Friedrich Schiller in seiner Antrittsvorlesung 'Was ist und $\mathrm{zu}$ welchem Ende studiert man Universalgeschichte' alle Völkerschaften um uns her, also um die normgebende europäische Kultur, gelagert sah. ${ }^{5}$ Europa musste notwendig das Entwicklungsziel, das ferne Ideal aller anderen Menschheitskulturen sein - dies stand außer Frage. Wir werden freilich noch sehen, wie auch diese Gewissheiten langsam erschüttert wurden. Dass dies ein Prozess ist, dessen Notwendigkeit bis heute anhält, gereicht nicht gerade zum Ruhme vorgeblicher europäischer Superiorität und Überlegenheit.

Sie sehen: Ein globalisiertes Selbstverständnis muss nicht notwendig mit einem globalen Verstehen gekoppelt sein, sondern kann dieses sogar verhindern. Dies wird gerade in dieser Passage, die eine Reihe sprachlicher Setzungen in der abendländisch-europäischen Kultur und ihren Diskursuniversen scheinbar erprobt, überaus deutlich. La Condamine gibt am Ende dieser Passage zu verstehen, dass die Indianer buchstäblich nicht bis drei zählen könnten. Eine angesichts der existierenden komplexen Zahlensysteme bei unterschiedlichen indigenen Kulturen ungeheuerliche Behauptung, die ganz gewiss auch nicht damit $\mathrm{zu}$ rechtfertigen ist, dass der Reisende ja nur en passant die Indianer besucht habe. Denn dieser Reisende in Bewegung erlaubt sich Urteile und Einschätzungen, die von ganz fundamentaler Bedeutung für die betroffenen Kulturen sind.

5 Vgl. Schiller, Friedrich: Was ist und zu welchem Ende studiert man Universalgeschichte? (Antrittsvorlesung in Jena, 26. Mai 1789). Jena: Akademische Buchhandlung 1789. 
Wir können hieran abschätzen, wie im Gewand wissenschaftlicher Objektivität die ungerechtfertigsten europäischen Vorurteile munter fortbestehen.

Gegen eine solche Einschätzung sollte sich Alexander von Humboldt später in seiner Relation historique, seinem eigentlichen Reisebericht von der amerikanischen Expedition, vehement aussprechen. Dabei ist es freilich erstaunlich, dass gerade diese Passage der Rechtfertigung indigener Zahlensysteme in den späteren Ausgaben seiner sogenannten Südamerikanischen Reise so beschnitten und gekürzt wurde, dass er gleichsam dem Argument La Condamines zuzustimmen scheint. Gleichzeitig wurde die gesamte lange und ausführliche Begründung, warum die Vorstellung, dass Indianer nicht einmal bis drei zählen könnten, falsch sei, 'versehentlich' aus seinem Text in dieser populären Ausgabe entfernt. Ein Schalk, der Böses dabei denkt! Auch dies mag ein Hinweis darauf sein, dass La Condamines Probleme bei weitem nicht nur Probleme des 18. Jahrhunderts sind sie haben sehr wohl etwas mit uns und unseren Vorurteilen heute zu tun. ${ }^{6}$

Mitten im 18. Jahrhundert, dem Jahrhundert der Aufklärung, versucht La Condamine, Aufklärung über die Existenz von Amazonen entlang jenes Flusses zu sammeln, dem diese sagenhaften kriegerischen Frauen - freilich gänzlich unschuldig - ihren Namen gaben. Bekanntlich ist die Sage von den Amazonen, jenen wehrhaften Frauen, die keine Männer unter sich dulden, sie nur einmal pro Jahr zu sich lassen, um den weiblichen Nachwuchs zu sichern, und ansonsten sich dadurch auszeichnen, dass sie sich eine Brust entfernen, um den Bogen besser spannen und ihre Pfeile besser abschießen zu können, ein überaus schöner Mythos aus der griechischen Antike, der bis heute die Literatur und die Künste beflügelt und beschäftigt hat. Dass diese männliche Obsession gen Westen projiziert wurde, wie es ab dem beginnenden 16. Jahrhundert geschah, ist die eine Sache; dass diese Vorstellung im 18. Jahrhundert nun im wissenschaftlichen Bereich weitergesponnen wurde, eine andere. La Condamine leistet hier im Sinne von Hans Blumenberg ganze 'Arbeit am Mythos'.

Als die Spanier und Portugiesen im 16. Jahrhundert den Amazonas hinauffuhren, glaubten sie in der Tat, derartige kriegerische Frauen zu erblicken. Dies war keineswegs etwas Neues, hatte doch auch schon Columbus in der Karibik vermeint, Amazonen im Meer der Antillen, der Vorinseln entdeckt zu haben, die auf einer eigenen Insel, einer reinen Fraueninsel, wohnen sollten. Die Übertragung durch die iberischen Conquistadoren auf den südamerikanischen Kontinentalbinnenraum war aber wesentlich dauerhafter, zumal die tropischen

6 Vgl. hierzu Ette, Ottmar: Alexander von Humboldt und die Globalisierung. Das Mobile des Wissens. Frankfurt am Main - Leipzig: Insel Verlag 2009, S. 277-295.

7 Vgl. Blumenberg, Hans: Arbeit am Mythos. Frankfurt am Main: Suhrkamp ${ }^{4} 1986$. 
Regenwaldgebiete am Amazonas noch für die Bedingungen des 18. Jahrhunderts so undurchdringlich waren, dass eine leichte Überprüfung dieses Mythos nicht möglich war.

So machte sich denn La Condamine an die delikate Sache und führte Befragungen bei den ortsanssässigen Indianern entlang der von ihm gewählten Flussroute durch, die ihm natürlich alle bestätigten, dass es solche kriegerischen Frauen in der Tat tief in den Regenwäldern verborgen gebe. Ein siebzigjähriger Indianer, leider vor kurzem verstorben, solle sie noch persönlich mit eigenen Augen gesehen haben - zumindest versichert sein Sohn glaubhaft, der Vater habe noch persönlich Amazonen gekannt.

Mithin schien niemand unter den Indianern am Vorhandensein und der tatsächlichen Existenz von Amazonen zu zweifeln. Die Indianer in den Tieflandgebieten hatten durch lange Erfahrungen mit den Weißen gelernt, dass man diese am schnellsten wieder loswerde, wenn man ihre Vorstellungen und Sehnsüchte - nach Gold und Silber, aber auch nach Sagen und Mythen - am einfachsten bejahte und bestätigte. La Condamine freilich schloss aus den verschiedenen Auskünften der von ihm an unterschiedlichen Orten befragten Indianer, dass es offensichtlich ein gemeinsames Rückzugsgebiet für die Amazonen geben müsse: die Berge von Guyana.

Zweifel kamen La Condamine freilich dennoch, müssten die benachbarten Indianerstämme doch, wie er in seiner Voyage sur l'Amazone festhält, zumindest von Zeit zu Zeit Nachrichten von diesen kriegerischen Frauen geben können. Doch La Condamine, nicht unerfahren in den Wendungen der europäischen Aufklärung, erklärt sich dies mit dem Verweis auf eine nation ambulante, die eben ständig ihren Wohnort wechsle. Auch Auflösungserscheinungen zieht La Condamine in Betracht: Möglich, dass sie erobert wurden, möglich aber auch, dass die Töchter den Ratschlägen der Mütter - oh heimliche süße Hoffnung der Männer nicht mehr länger gefolgt seien und sich nun doch wieder mit Männern dauerhaft verbunden hätten. Überflüssig hinzuzusetzen: Wir befinden uns hier im Reich der freien Spekulation, der freien Erfindung.

Damit ist eines für La Condamine gewiss: Selbst wenn man heute keine Amazonen mehr antreffen würde, so bedeutete dies nicht, dass es niemals Amazonen gegeben hätte. Außerdem erweitert La Condamine den Definitionsbereich von Amazone - Sie wissen, wir Heutigen verstehen darunter schlicht eine Reiterin -, indem er betonte, es würde reichen, wenn diese Frauen nur einmal im Jahr Männer zu sich ließen. Sie müssten sich nicht auch - wie dies einst Acuña berichtet hatte - zusätzlich auch noch eine Brust abgeschnitten haben. ${ }^{8}$ Es gebe

8 Vgl. La Condamine, Charles-Marie de: Voyage sur l'Amazone, S. 87. 


\section{LES SINGVIARITEZ}

mieres A mazones. Elles font guerre ordinairemét contre quelques autres nations: \& traitent fort inhumainecönse les ment ceux qu'elles peutent prendre en guerre. Pourles Amdzo faire mourir elles les pendent par vine iambe à quelque nes tri-
Tét ctux haute branche d'vn arbre:pourl'auoir ainfilaiffé quelque

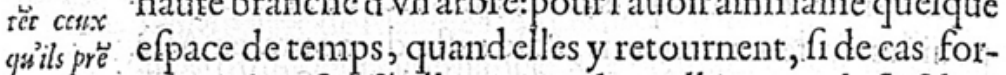
nent en tuit n'eft trefpaffé, elles tirerót dix mille coups de flefches: gucre. \& ne le mangent commeles autres Sauuages,ains le paffent par le feu,tant quil eft reduit en cendres. D'auanta-

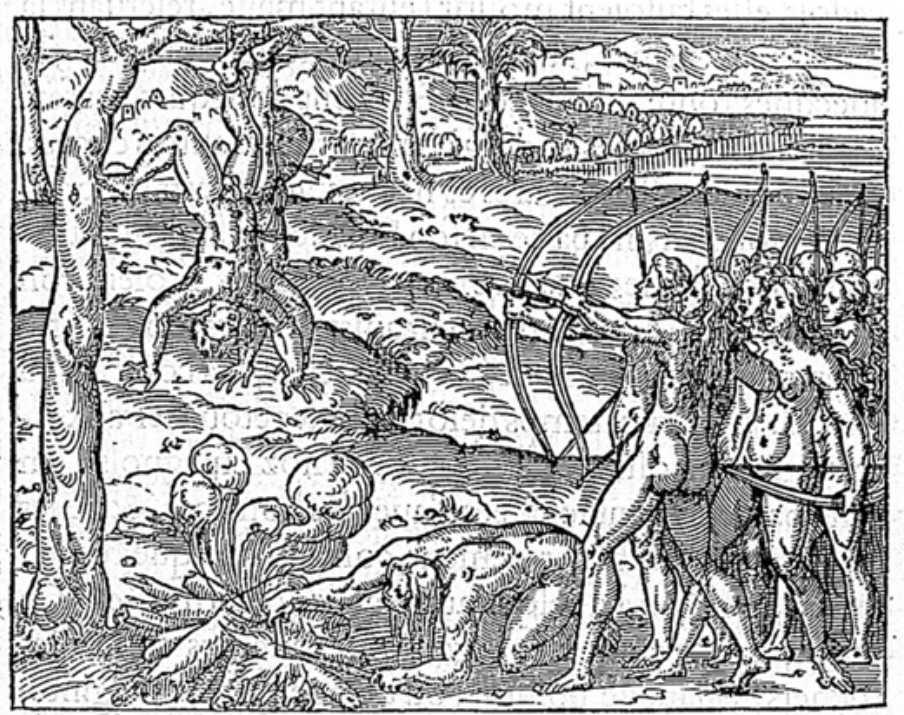

origine gecesfermmes approchans pour combatre, iettent hordes $A$ - tribles $\&$ merueil leux criss, pour efpouuéter leurs ennemis: mazo- Del'origine de cés Annazones en ce païsn'eft facile d'en nes. Ame efcrire aut certain. Aucunstiennent, quapres la guerre de

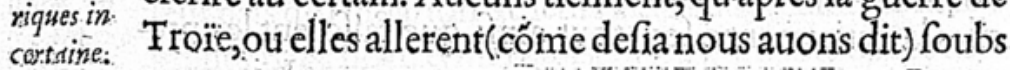

Abb. 63: Kriegerische Amazonen in Les singularitez de la France antarctique von André Thevet, 1558.

Reiseberichte genug, so La Condamine, die das Vorhandensein derartiger Amazonen, freilich mit beiden Brüsten, bestätigt hätten. Der Mythos lebte!

Mythenkritisch, wie die europäischen Aufklärer nun einmal waren, betonte La Condamine, dass die Indianer starrköpfig, dem Wunderbaren stets 
erliegend, erzählsüchtig und unglaubwürdig seien, dass aber niemand von ihnen jemals von den Amazonen des Diodorus von Sizilien gehört habe, so dass letztlich ihre Glaubwürdigkeit in diesen Dingen nicht leicht erschüttert werden könne. Und als ein starkes Argument könne schließlich auch die Tatsache gelten, dass sich der Amazonenmythos bei allen Indianern in Amerika finde, nicht nur bei jenen, die den tropischen Regenwald entlang des Amazonas bevölkern. Auch die unterschiedlichsten europäischen Autoren hätten von den Amazonen gesprochen: So etwa Amerigo Vespucci, Ulrich Schmidl, Walter Raleigh und so viele mehr. Damit verwies La Condamine freilich auf Autoren, welche - wie wir heute wissen - nicht weniger starrköpfig, am Wunderbaren ausgerichtet und erzählsüchtig waren als jene Indianer, von denen La Condamine uns tendenziös berichtete.

Ein weiteres Forschungsgebiet, in welches La Condamine etwas Licht bringen sollte, ist das der Frage einer Flussverbindung zwischen Orinoco und Amazonas. Es gab verschiedenste Hinweise darauf, dass diese Verbindung über die Gabelteilung des Casiquiare liefe, von der die Zeitgenossen seit dem 17. Jahrhundert wussten. Wir wissen heute, dass es diese Verbindung über die berühmte Bifurkation des Casiquiare gibt. Doch unter den französischen Zeitgenossen La Condamines war sie stets umstrittn; trotz La Condamines bestätigender Berichte wurde die Gabelteilung wenige Jahrzehnte später von einer in Frankreich überhand nehmenden sogenannten systematischen Geographie kurzerhand für unmöglich erklärt: $\mathrm{Zu}$ sehr war man in hierarchisierten Bezügen von Hauptfluss und Nebenflüssen gefangen, als dass man sich nicht-hierarchische, netzartige Flusssysteme ohne Weiteres hätte vorstellen können. So konnte nicht sein, was nicht sein durfte.

Wir wissen heute, dass es nicht notwendig ist, in die Tropen zu reisen, um eine Bifurkation zu sehen; denn auch in unseren Breiten gibt es eine Gabelteilung, nämlich die zwischen Hase und Hunte im norddeutschen Tiefland. Dies war aber damals nicht bekannt. Als Beleg für die Existenz der Bifurkation des Casiquiare zwischen Orinoco und Amazonas führte La Condamine den Bericht einer Indianerin an, die vom Orinoco über den Río Negro bis nach Pará an der Amazonasmündung gefahren sei. ${ }^{9}$ Auch die Jesuitenoberen besuchten sich gegenseitig über diese Flussverbindung - aber konnte man denn als Aufklärer, der etwas auf sich hielt, diesen Jesuitenberichten trauen?

Für La Condamine freilich stand fest, dass man eine derartige Flussverbindung nicht mehr in Frage stellen konnte, auch wenn 1741 der Autor des Orinoco

9 Vgl. ebda., S. $92 \mathrm{f}$. 
ilustrado, Pater Gumilla, dies noch für gänzlich unmöglich erklärt hatte. Unser französischer Reisender verwies darauf, dass die Flussverbindung sehr wohl auf den alten Karten verzeichnet gewesen sei; allein die neueren Geographen (sprich Kartographen) hätten sie auf ihren Karten unterdrückt.

So kam denn auch La Condamine endlich in den Genuss dieses Gefühls, ein wahrer Entdecker zu sein, sei es ihm doch gelungen, trotz derlei konträrer Einschätzungen in Europa die Existenz der Flussverbindung zu belegen. Die Argumentationslinie des französischen Reisenden und académicien ist dabei aufschlussreich:

La communication de l'Orinoque et de l'Amazone, récemment avérée, peut d'autant plus passer pour une découverte en géographie que, quoique la jonction de ces deux fleuves soit marquée sans aucune équivoque sur les cartes anciennes, tous les géographes modernes l'avaient supprimée dans les nouvelles, comme de concert, et qu'elle était traitée de chimérique par ceux qui semblaient devoir être le mieux informés de sa réalité. Ce n'est probablement pas la première fois que les vraisemblances et les conjectures purement plausibles l'ont emporté sur des faits attestés par des relations de voyages, et que l'esprit de critique poussé trop loin a fait nier décisivement ce dont il était seulement encore permis de douter. ${ }^{10}$

Sie sehen, dass Charles-Marie de La Condamine diese Frage sehr bewusst in den Kontext der Glaubwürdigkeit und damit auch der Quellenbasis für Positionen von Aufklärern stellt: Denn es war in der Tat eine ganz grundsätzliche Frage, um die es an dieser Stelle ging. Die Problematik der Glaubhaftigkeit der Reiseberichte wirft erneut das Problem einer Scheidung zwischen Reisenden und Daheimgebliebenen, zwischen den Augenzeugen und den Fabrikanten von Theorien auf, die im fernen Europa und ohne jede Kenntnis vor Ort zu beurteilen versuchten, wie es in der Realität der Kolonialländer aussehen konnte. Das war nun wirklich keine leichte Aufgabe. Und wir werden gleich im nächsten Teil sehen, dass sich daran eine der grundlegenden Debatten entzündete, welche das 18. Jahrhundert nicht nur in Europa, sondern gerade auch außerhalb Europas in Rage versetzte. Denn es gab, soviel sei schon vorausgeschickt, sehr wohl eine Aufklärung auch außerhalb Europas, auch wenn diese Tatsache von Europa über einen langen Zeitraum und bis hinein in unsere Tage beständig geleugnet worden ist.

Allerdings sehen wir an diesem Beispiel auch, wie sehr sich in La Condamines Reisebericht ebenfalls das Hörensagen mit den Messungen und den Mythen zu einer solchen Mischung und Mixtur verbinden, dass es schlechterdings nicht mehr möglich ist, die Theorie (oder die Konventionen) vom eigenen Sehen, von

10 Ebda., S. 93. 
der eigenen Augenzeugenschaft zu trennen. Denn selbstverständlich sind unsere Blicke längst kodiert, unterscheiden scheinbar Wichtiges von scheinbar Unwichtigem, ja das Richtige vom vermeintlich Unrichtigen, noch bevor wir sie auf eine uns neue Welt richten. Dieses Verhältnis zwischen Reisen und Schreiben wird von unserem Autor freilich nicht reflektiert; er bewegt sich in der Neuen Welt mit einer Sicherheit des Verstehens, für das man sich die Unsicherheit und das Tastende eines Michel de Montaigne dringlich gewünscht hätte.

Gerade die Reiseberichte des 18. Jahrhunderts führen uns dies in aller Deutlichkeit vor Augen. Ebenso wie das beständige Verlangen der Europäer, in fremden Weltgegenden als Entdecker aufzutreten, also den europäischen Entdeckungsgeist gleichsam zu verkörpern oder in der eigenen Figur zu personalisieren. Dies gilt auch für La Condamine, der hier von einem neuen Mesopotamien spricht und fast bruchlos auf den Mythos vom Dorado wie auch vom Mythos von Manoa zu sprechen kommt, einer Stadt aus purem Gold. ${ }^{11}$ Es gibt hier Wegbeschreibungen und Passagen, die zeitweise aber unter Wasser gesetzt sind, so dass alles über den Zugang zu dieser sagenhaften Stadt in der Tat an Alejo Carpentiers wunderbaren Roman Los pasos perdidos erinnert, der sich mit der Literatur rund um den Orinoco und seinen Mythen sehr gut auskannte. La Condamine freilich machte - mythenkritisch wie immer auf seine eigene Weise - einfach Abstriche, da vieles übertrieben worden sei: Am Grundsätzlichen mochte er jedoch nicht rütteln, sondern verwies auf die üblichen Reiseberichte.

So ging es im Bericht des Franzosen Stück für Stück den Amazonas in Richtung seiner Mündung hinunter. Schließlich traf La Condamine am 19. September 1743 in Pará an der Amazonasmündung ein (vgl. Abb. 62: La Condamines Reiseroute). Vier Monate waren seit seiner Abreise aus Cuenca im Andenhochland vergangen. An diesem Punkt seiner Reise angelangt, glaubte sich der Franzose nun bereits nach Europa versetzt, in eine Stadt mit geraden Straßen, mit Häusern aus Stein und allen Bequemlichkeiten, welche die europäische Zivilisation dem Reisenden bieten konnten. ${ }^{12}$

Es folgte darauf die Rückreise in eine französisch beherrschte Region des amerikanischen Subkontinents und damit eine etwa zweimonatige Schifffahrt von der Amazonasmündung nach Cayenne, das Ihnen zumindest als jener Ort bekannt sein dürfte, wo der Pfeffer wächst. Die Reisenden finden sich am 26. Februar 1744 erstmals wieder in einer französischen Kolonie, wobei La

11 Vgl. ebda., S. $95 \mathrm{f}$.

12 Vgl. ebda., S. 117. 
Condamine als Wissenschaftler der Aufklärung auch in dieser französischen Besitzung nun noch mancherlei Versuche und Experimente durchführte, mit denen wir uns aber nicht mehr weiter beschäftigen müssen.

In etwas mehr als sechzehn Stunden wird die Weiterreise von Cayenne zum Fluss Surinam bewerkstelligt, wo man im August 1744 ankommt. dort geht es dann flussaufwärts weiter nach Paramaribo, der Hauptstadt der holländischen Kolonie Suriname. Von dort aus schifft man sich dann auf einem holländischen Kauffahrer nach Amsterdam ein, um den Atlantik zu überqueren. Im November 1744 ist man schließlich wieder im Ärmelkanal, wo das niederländische Kaufmannsschiff prompt von einem Korsaren aus Saint-Malo bedroht wird, der laut La Condamine zumindest höflicher ist als jener englische Korsar, der das Schiff noch vor der Küste Amerikas zu kapern gedroht hatte. Französische Korsaren haben wenigstens Manieren! Im Februar 1745 trifft La Condamine dann wieder in Paris ein, insgesamt fast zehn Jahre nach seiner Abreise aus der französischen Hauptstadt. Reisen konnten im 18. Jahrhundert eben dauern.

La Condamines Reisebericht wurde, wie ich schon betonte, eine sehr positive Aufnahme zuteil. Doch sein nicht minderer, vielleicht sogar größerer Ruhm ging auf eine literarische Bearbeitung seines Reiseweges durch einen Freund zurück, der ihm schon manches Mal beigestanden hatte. Lassen Sie mich also kurz auf einen kleinen Text verweisen, der - in einer typischen Herausgeberfiktion - in deutscher Sprache in Minden im Jahre des Herrn 1759 gefunden worden sein soll und von einem gewissen Voltaire unter dem Titel Candide ou l'optimisme veröffentlicht wurde.

Ich möchte an dieser Stelle keineswegs auf eine Gesamtdeutung dieses wunderschönen und wunderschön komplexen Textes zusteuern, Ihnen wohl aber bewusst machen, wie sehr die Reflexion über die außereuropäischen Weltregionen und Kulturen, aber auch über den außerhalb Europas von den Europäern expansiv betriebenen Kolonialismus die Literatur des 18. Jahrhunderts in Frankreich wie im Rest des alten Kontinents prägten. Daher sollten wir uns kurz ansehen, was dem arglosen Candide, der im schönen Westfalen im Schloss des Barons von Thunder-ten-tronckh erzogen wurde, in Amerika zustieß.

Voltaire nutzt seinen conte philosophique dahingehend aus, dass er in ihm die unteschiedlichsten 'angesagten' Themenbereiche behandelt, die sich für die zeitgenössische Leserschaft mit den amerikanischen Kolonien verbinden. So hält sich sein Candide ganz selbstverständlich - ich komme später noch auf dieses Thema zu sprechen - bei den Jesuiten in Paraguay auf, gilt ihr Herrschaftsbereich doch für lange Zeit als der geographisch eingrenzbare Ort einer neuen Utopie, eines neuen Gottesstaates christlicher Prägung. Ein gefundenes Fressen für einen Antiklerikalen wie Voltaire! 


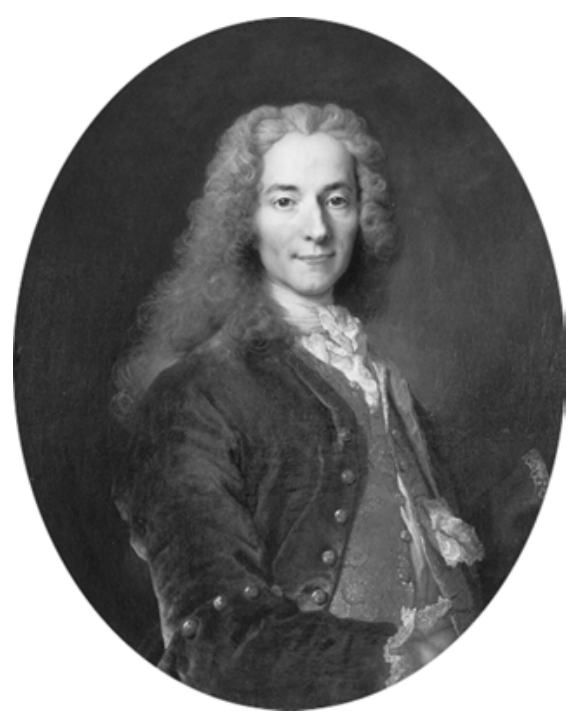

Abb. 64: Voltaire (François Marie Arouet) (Paris, 1694 - ebenda, 1778).

Die Jesuiten hatten im Landesinneren Südamerikas ein eigenes Reich, geradezu einen eigenen Staat errichtet, der keinen weltlichen Maßregelungen iberischer oder europäischer Kolonialpolitik unterlag. Unser Candide schaut sich aufmerksam und kritisch in diesem Jesuitenreich um und stößt auf allerlei Abscheuliches. Danach folgt Voltaires Protagonist in einem conte philosophique, der mit ungeheuer beschleunigten raumzeitlichen Koordinaten arbeitet, dann recht genau der Route unseres guten La Condamine, so dass er, wen wundert's, geradezu notwendig nach Eldorado kommen muss und damit einen der großen Mythen, die Amerika für die Europäer bereit hielt, weiter zu bearbeiten vermag.

Bei der Annäherung an dieses Land lässt Cacambo, der Begleiter Candides, freilich keinen Zweifel daran, dass die amerikanische Hemisphäre keineswegs besser sei als die andere, also die altweltliche. ${ }^{13}$ Voltaire vermeidet alles, was die Amerikas in ein besseres Licht rücken könnte als das einheimische Europa dies war selbstverständlich schon beim Jesuitenstaat von Paraguay der Fall gewesen. Und doch glaubt Candide bei seiner ersten Annäherung an das Land von Eldorado zu vermeinen, es handle sich dabei um ein besseres Land als das seines Westfalens und seines Minden, das er einst hinter sich gelassen hatte.

13 Vgl. Voltaire: Candide ou l'optimisme. Paris : Classiques Garnier 1913, S. 174 f. 
So nähert sich Candide mit seiner aufgeschlossenen Leserschaft jenem Eldorado an, das La Condamine auf seiner Reise noch verschlossen blieb. Er erfährt von einem Manne im biblischen Alter, dass dies die eigentliche Heimat der Incas sei und dass Europa dieses Land immer wieder bedroht habe, dass letztlich aber weder die Spanier noch die Engländer mit ihrem Raleigh genauere Kenntnis dieses Landes erhalten hätten. ${ }^{14}$

Hier ist nun endlich ein Land, in dem es keine Mönche gibt, welche regieren, herrschen, intrigieren und jene Leute verbrennen, die nicht ihrer Ansicht und Überzeugung sind. Folglich glaubt sich Candide dem von ihm gesuchten und ersehnten Traumlande nahe, wo alles aufs Beste eingerichtet ist und ein glückliches Gemeinwesen herrscht. Hätte nur sein Philosoph Pangloss dieses Land gesehen, seufzt Candide, er würde nicht mehr behaupten, dass das Schloss Thunder-ten-tronckh das Beste sei, was es auf Erden gebe. Sie sehen, Voltaire spielt mit der Differenz zwischen den Reisenden und den Daheimgebliebenen, wobei er letzteren freilich das längere Ende lässt. Kein Wunder, zählte er selbst doch auch nicht zu jenen Philosophen, von denen sich Rousseau im zweiten Discours wünschte, sie würden sich auf eine Weltreise begeben. Aber mit dieser Fragestellung und Herausforderung werden wir uns noch ausführlich in der Vorlesung befassen. Klar ist freilich schon jetzt, dass es Rousseau um ein verändertes Verhältnis von Reisen und Schreiben ging.

Genau auf eine solche Weltreise aber begab sich unser Candide. Der Ehrgeiz treibt die Europäer vorwärts und geradewegs aus dem Glück hinaus, wie der König von Eldorado, wo es übrigens auch keine Gefangenen und Eingekerkerten gibt, sehr wohl bemerkt. ${ }^{15}$ So reisen Cacambo und Candide denn weiter nach Surinam, wo sie mit den Schrecken des europäischen Kolonialismus konfrontiert werden. Voltaire wählte hierfür vorsichtshalber nicht das französische Herrschaftsgebiet (und heutige Überseedepartement) Guyane, das heute in Europa vor allem dafür bekannt ist, dass von dort aus die europäischen Trägerraketen für allerlei Satelliten starten. Nein, er wählte vielmehr klug die holländische Kolonie, vielleicht auch um französische Empfindlichkeiten zu schonen, die einer Akzeptanz der Darstellung von Gräueltaten sowie einer beißenden Kritik hieran wohl im Wege gestanden hätten.

Hier können sich in Suriname die europäischen Reisenden der Tatsache versichern, zu welchem Preise man in Europa den ach so süßen Zucker genieße. ${ }^{16}$ Denn schnell wird klar, was hier den Sklaven angetan wird, in welcher

14 Ebda., S. 178.

15 Ebda., S. 180.

16 Ebda. S. 182. 
Weise sie grundsätzlich und selbstverständlich misshandelt werden und überdies noch Hohn und Spott über sie ausgegossen wird. Nein, dies konnte nicht das von Candide ersehnte Land sein!

An dieser Stelle nun geht der conte philosophique unmittelbar in eine scharfe Kolonialismuskritik über, freilich nicht des französischen Kolonialismus, sondern vorsichtshalber des holländischen Kolonialismus, der in Frankreich in keinem guten Rufe stand. Doch mag dieser für Voltaire als pars pro toto für den europäischen Kolonialismus in seiner Gänze stehen. So trifft Candide in Suriname auf einen schwarzen Sklaven, dem die rechte Hand und das linke Bein fehlen, der halbnackt am Boden liegt und, wie er gleich erzählen wird, von seiner Mutter aus Guinea für einige patagonische Münzen - Voltaire nimmt es hier geographisch nicht so genau - in die Sklaverei verkauft worden war. Hören wir das Zeugnis dieses bedauernswerten Sklaven, der in Voltaires conte philosophique für die gesamten Gräuel der Europäer stellvertretend als Opfer steht:

'Eh! mon Dieu! lui dit Candide en hollandais, que fais-tu là, mon ami, dans l'état horrible où je te vois? - J'attends mon maître, $M$. Vanderdendur, le fameux négociant, répondit le nègre. - Est-ce $M$. Vanderdendur, dit Candide, qui t'a traité ainsi? - Oui, monsieur, dit le nègre, c'est l'usage. On nous donne un caleçon de toile pour tout vêtement deux fois l'année. Quand nous travaillons aux sucreries, et que la meule nous attrape le doigt, on nous coupe la main; quand nous voulons nous enfuir, on nous coupe la jambe: je me suis trouvé dans les deux cas. C'est à ce prix que vous mangez du sucre en Europe. ${ }^{17}$

Gewiß, wir sind in einem conte philosophique, der sich der Form des literarischen Reiseberichts bedient, und nicht in einer Abhandlung mit abolitionistischem Grundton, die auf eine Abschaffung der Sklaverei abzielte. Doch deutlicher kann eine Kolonialismuskritik nicht ausfallen. Denn hier werden Grausamkeiten aufgezeigt, die in das Jahrhundert der Aufklärung bei weitem nicht zu passen scheinen. Die Literatur wird in diesem conte philosophique zu jenem Experimentierfeld, in welchem die Möglichkeiten des Imaginierbaren und Denkbaren erprobt und in das Schreibbare umgesetzt werden, lange bevor sie in der Wirklichkeit etwa als tatsächliche politische Maßnahmen erprobt werden können. Der Literatur ist eine prospektive Funktion eigen, die auf künftige Veränderungen zielt, welche zunächst auf dem Gebiet der Fiktion durchgespielt und erprobt werden müssen.

Die Realität sah immer noch anders aus. Noch ist die Haitianische Revolution Jahrzehnte entfernt. Und nicht nur Guillaume-Thomas Raynal, die zentrale Autorfigur der Histoire philosophique et politique des établissements des Européens dans les deux Indes, der großen französischen Kolonialenzyklopädie des

17 Ebda. 
18. Jahrhunderts, die mit Angriffen gegen die Sklaverei nur so gespickt ist, sondern auch Voltaire selbst, der wie Raynal Besucher und Gast am Hofe Friedrichs des Großen in Sanssouci war, besaßen realiter Aktien in diesem Zucker- und Sklavenhandelsgeschäft. Diese Tatsache entwertet zwar nicht ihre Kolonialismuskritik, lässt sie gleichwohl aber in einem anderen, widersprüchlicheren, komplexeren Licht erscheinen.

Die Allgegenwart dieser Problematik und die Präsenz der außereuropäischen Welt in den Literaturen Europas, die an vielen anderen Beispielen der Zeit hätte aufgezeigt und belegt werden können, sei anhand dieses kleinen Beispiels, das so oft überlesen wird, einmal mehr unterstrichen. Wir wollen uns in der unmittelbaren Fortführung unserer Vorlesung ausführlicher mit derlei Problemstellungen beschäftigen und dabei vor allem danach fragen, wie denn im Kontext des Gegensatzes zwischen Reisenden und Daheimgebliebenen und vor dem Hintergrund der zahlreichen europäischen Reiseberichte, in denen die Neue Welt behandelt wurde, das Verhältnis zwischen Alter und Neuer Welt neu angesprochen und bestimmt wurde.

Als unseren Auktor und Gewährsmann nehmen wir dabei einen Reisenden und Reiseschriftsteller, dessen Name längst wieder in die Dunkelheit zurückfiel, aus welcher er kam. Allein in jener Debatte, welche unter dem Namen der 'Berliner Debatte um die Neue Welt' in die Geschichte einging und zu jenen verschütteten Traditionen zählt, die in neuerer Zeit wieder ausgegraben wurden, leuchtet sein Name noch hell. Es ist eine Debatte, die sich gleichsam vor unserer Haustüre abspielte und die uns zeigt, dass wir hier an der Universität Potsdam in den wunderbaren historischen Gebäuden, die uns direkt mit dem 18. Jahrhundert verbinden, hautnah am Geschehen, das wir diskutieren wollen, dran sind. 